\title{
Justicia de aguas y vínculos comunitarios (San Martín, Mendoza, Argentina), $1814-1859^{*}$
}

\author{
Water Justice and Community Bonds \\ (San Martín, Mendoza, Argentina), 1814-1859
}

\author{
Eugenia Molina \\ (D) http://orcid.org/0000-0002-2891-5224 \\ Facultad de Filosofía y Letras \\ Conicet-Universidad Nacional de Cuyo, Argentina \\ eramolina@hotmail.com
}

Resumen: En este trabajo se indagan las prácticas y representaciones que regulaban la justicia de aguas en un territorio periférico de la provincia de Mendoza, durante y después de la revolución. La hipótesis sostiene que la espacialización política de este territorio ubicado al sureste de la campaña mendocina estuvo conectada con la propia dinámica de los lazos que pobladores y propietarios establecieron entre ellos más allá de la voluntad ordenadora de los gobiernos. Se aborda un territorio alejado del centro de poder porque se cree que es un observatorio especial para ver la relación entre proyectos de estatalidad y comportamientos de comunidades activas en la gestión de sus

* Este trabajo se enmarca en el PICT "Tradición jurídica y discursividad política en el siglo xIx. La emergencia de una cultura estatal. Río de la Plata-Argentina”, Agencia Nacional de Promoción Científica y Tecnológica. Investigador responsable: Dr. Alejandro Agüero. Código: PICT 2014-3408.

cómo citar: Molina, E. (2019). Justicia de aguas y vínculos comunitarios (San Martín, Mendoza, Argentina), 1814-1859. Secuencia (105), e1515. Dor: https://doi.org/10.18234/secuencia.v0i105.1515

cC Esta obra está protegida bajo una Licencia Creative Commons Atribución-NoComercial 4.0 Internacional. 
recursos y, por lo tanto, quizá más alerta respecto de intromisiones gubernamentales inéditas.

Palabras clave: justicia; gestión hídrica; estatalidad; disciplinamiento; vínculos comunitarios.

Abstract: This article investigates the practices and representations that regulated water justice in a peripheral territory of the province of Mendoza, during and after the Revolution. The hypothesis posits that the political spatialization of this territory located southeast of the Mendoza campaign was connected to the dynamics of the ties the settlers and owners established among themselves beyond the will of governments. A territory away from the center of power is analyzed because it is believed to be a special observatory for observing the relationship between statehood projects and the behavior of communities active in the management of their resources and, therefore, perhaps more alert to unprecedented government intromissions.

Key words: justice; water management; statehood; discipline; community bonds.

Fecha de recepción: 26 de mayo de 2017 Fecha de aceptación: 14 de noviembre de 2017

$\mathrm{H}$ asta comienzos del siglo XIX un amplio ángulo entre los ríos Mendoza y Tunuyán, a unos $40 \mathrm{~km}$ al sureste de la ciudad, no había atraído la atención de las autoridades coloniales debido a las ciénagas que dificultaban la agricultura y la ganadería. No obstante, un empadronamiento de fines de 1810 evidenció que contaba con varias propiedades en las que una articulación intensa entre diversas formas de acceso a la tierra y una negociada distribución del agua pudo haber creado un escenario muy específico para cierta justicia de proximidad (Barriera, 2012a, 2012b; Molina y Yangilevich, 2015; Sanjurjo, 2015), que como modalidad gubernamental buscaba garantizar la armonía 
comunitaria. ${ }^{1}$ Este trabajo analiza precisamente las prácticas y representaciones que regularon allí la justicia de aguas para observar cómo criterios del derecho indiano ${ }^{2}$ pervivieron y se reformularon luego de la revolución, contribuyendo a configurar los vínculos poblacionales y las relaciones de estos con las autoridades en el marco de la estatalidad provincial luego de 1820.

La hipótesis sostiene que la espacialización política de este territorio 3 estuvo conectada con la propia dinámica de los lazos que los pobladores mantuvieron más allá de la voluntad ordenadora de los gobiernos. En ellos, la gestión del agua habría actuado como eje articulador de las relaciones comunitarias dadas las características geomorfológicas e hídricas que hacían necesario cierto control para evitar inundaciones y ciénagas, como para regular la llegada del recurso hasta sectores que repetían las condiciones de aridez general fuera de los oasis mendocinos. Esto explicaría que las comunidades de regantes adquirieran un papel clave en la gestión de este recurso de uso común aun cuando las autoridades intervinieran con reglamentaciones y vigilancias crecientes.

${ }^{1}$ Utilizamos relaciones "comunitarias" siguiendo las consideraciones de Weber respecto de la distinción entre comunidad y sociedad, por lo cual, si las primeras implicarían contactos cotidianos asegurados por la proximidad de residencia y un conocimiento personal, las segundas conllevarían lazos mediatizados (Weber, 1969, pp. 293-296).

${ }^{2}$ Un conjunto de principios doctrinarios, legislación de diverso origen y jurisprudencia conformaba una nutrida cultura, aunque siempre se producía un proceso de "localización", esto es, de apropiación en cada jurisdicción de esa pluralidad jurídica para atender las necesidades inmediatas de la población y sus costumbres (estas también fuentes de derecho), lo cual estimulaba la producción normativa local (Agüero, 2013). Análisis sobre el derecho de aguas en la América española y en Río de la Plata en Doucet (1983); Dougnac Rodríguez (1984, 1985); Dougnac Rodríguez y Barrientos Grandón (1991); Mariluz Urquijo (1951); Martínez (1970); Pascualotto (2017); Sanjurjo (2011); Vives (1990).

${ }^{3}$ Se distingue entre territorio y espacio político por resultar operativo para evidenciar procesos que pueden estar relacionados pero que no siempre son coincidentes. Mientras el primero apuntaría a los vínculos entre una población, las tierras que ocupa y las autoridades que gobierna el cuerpo político, el segundo implicaría un diseño institucional que implementaría una red de agentes para convertir una extensión en una organización con objetivos determinados. Así, si los procesos de territorialización darían cuenta de dinámicas en las que las sociedades, sus relaciones internas, con las autoridades y con sus medios de producción serían clave, los de espacialización política referirían a voluntades de asignación de funcionarios y jerarquización de recursos que podrían o no prestar atención a esas dinámicas. Esta conceptualización es deudora de las formulaciones de Darío Barriera (2015). 
Si bien el abordaje sigue una opción microanalítica busca aportar elementos al campo de discusión que se ocupa de los procesos de estatalidad. ${ }^{4}$ Se pretende pensar cómo se conformó el Estado provincial en los márgenes, en territorios no inmediatos al centro de poder, en donde comunidades activas en la gestión de sus recursos pudieron estar quizá más alerta respecto de intromisiones gubernamentales inéditas. El mirador que ofrecen las prácticas de justicia de aguas en este departamento de Mendoza puede resultar fructífero para seguir la configuración estatal en las relaciones cotidianas de las poblaciones que experimentaron su conformación y cómo su accionar se articuló con los esfuerzos disciplinadores del Estado. En esta línea, ya diversos estudios sobre el oriente español han dado cuenta de experiencias de comunidades de regantes de larga data que se reacomodaron a diferentes contextos políticos durante la modernidad y el siglo xIx, hasta llegar a la actualidad, manteniendo relaciones de colaboración, conflicto y negociación con las estructuras e instituciones estatales (Calatayud, 2016; Calatayud y Garrido, 2012). De hecho, estas prácticas de gestión colectiva del agua de tan larga duración sirvieron de material empírico a la elaboración teórica de Ostrom (2000) sobre la potencialidad positiva de la administración comunitaria de los recursos de uso común, ${ }^{5}$ aunque algunas de sus consideraciones han sido

${ }^{4}$ Son amplias las discusiones sobre esta problemática en las últimas décadas. Una de las operaciones intelectuales ha consistido en mostrar cómo las visiones teleológicas decimonónicas aplicaron al pasado categorías estatalistas que el Estado ha sido exitoso en naturalizar dentro de las prácticas historiográficas (Abrams, 1988; Bourdieu, 1996; Corrigan y Sayer, 1985, pp. 1-13; Guha, 2002, pp. 17-20). Otras líneas se han ocupado de mostrar cómo el proceso no sólo se desplegó de arriba hacia abajo, sino también desde los márgenes (sociales, culturales y geográficos), revelando los límites de la centralización y la necesidad de reflexionar sobre ellos dada su labilidad aún en las configuraciones contemporáneas (Das y Poole, 2008; Mitchell, 1991). La cuestión de la justicia, a su vez, se ha convertido en tópico de investigación privilegiado en relación con la configuración estatal; a modo ilustrativo del debate actual en el campo iberoamericano, véase la presentación y el dossier coordinado por Irurozqui (2016) y el balance historiográfico de Galante (2011).

${ }^{5}$ La propuesta teórica de Elinor Ostrom sobre la gestión de los recursos de uso común ha revalorizado la acción colectiva de comunidades autorreguladas como alternativa organizacional frente al Estado y la intervención privada. Desde la perspectiva de la Economía Institucional, sistematizó los aportes que estudios empíricos habían realizado de distintas experiencias para concluir en que la participación de los propios interesados en la provisión y distribución de sus recursos, siempre que se concreten una serie de condiciones, garantiza cierto éxito de eficiencia y eficacia respecto de su sostenibilidad (Ostrom, 2000, p. 11). El impacto de sus reflexiones, las cuales discutieron la tesis de Garrett Hardin sobre la "tragedia de los comunes", ha resultado fundamental para repensar las modalidades de administración colectiva, renovando la agenda de investigación (Ingold, 2008), marcando la necesidad de atenderla en su relación con las es- 
revisadas por abordajes que evidenciaron cómo caracteres que la autora consideró obstaculizadores de una gestión exitosa, fueron los que tuvieron efectivamente las comunidades de regantes del este de España plurisecularmente, y que a pesar de ello lograron una continuidad y eficacia notables (Garrido, 2011). Como se observa, las relaciones entre los usos del agua y las configuraciones estatales conforman una vía de abordaje productiva para analizar las modalidades adquiridas por estas últimas, como también para comprender formas colectivas respecto de los primeros que pueden aportar elementos para repensar las prácticas actuales.

La exposición se organizará en tres apartados. Primero se describirán los caracteres del territorio que comenzó a consolidarse en este sector de la campaña mendocina y qué prácticas regulaban por entonces la gestión hídrica. Posteriormente se abordará la organización de la jurisdicción de aguas en relación con los esfuerzos ordenadores durante la década revolucionaria y después de la desaparición del Cabildo en 1825. Finalmente, se analizará el papel de las comunidades de regantes en la regulación de sus recursos y en relación con los gobiernos. La periodización toma fechas relevantes para el objeto de estudio: 1814, cuando se designaron los primeros jueces en este territorio y, 1859, año en el que el núcleo oriental del departamento de San Martín se escindió para formar otro nuevo, el de Junín (en torno a la villa de Retamo), desarticulando administrativamente relaciones comunitarias de larga data. Este artículo lo he trabajado con expedientes originales del Archivo General de la Provincia de Mendoza y con compilaciones de obras editadas como fuentes.

\section{ENTRE CIÉNAGAS Y ALFALFARES: TRAYECTOS DE ESPACIALIZACIÓN POLÍTICA}

La ciudad de Mendoza había sido ciudad principal del Corregimiento de Cuyo, dependiente de la jurisdicción de Santiago de Chile hasta 1776, cuando este fue incorporado al virreinato del Río de la Plata; no obstante, la aplicación de la Real Ordenanza de Intendentes disolvió esta unidad, con lo cual la ciudad, junto a San Juan y San Luis, pasó a estar subordinada a la nueva capital intendencial establecida en Córdoba. Cuando en junio de 1810 la elite

tructuras de poder, los procesos de institucionalización de sus prácticas y sus niveles de éxito en la conservación de los sistemas de riego y del recurso mismo (Pérez Picazo, 2000, p. 48). 
mendocina asumió la opción revolucionaria encabezada por Buenos Aires, rompió la cadena de mando que la unía a aquella, y comenzó a recibir tenientes de gobernador desde esta (excepto durante 1811 cuando rigió el reglamento de juntas). Sin embargo, a fines de 1813 el gobierno revolucionario decidió crear la Intendencia de Cuyo con Mendoza como centro, reincorporando los lazos institucionales como subordinadas de San Juan y San Luis, hasta que en 1820 se desarticuló en el marco de la crisis generalizada del Río de la Plata.

El paraje de Barriales, núcleo territorial inicial en el que se focaliza este trabajo, se ubicaba en el ángulo que formaban los ríos Mendoza y Tunuyán, a unos $40 \mathrm{~km}$ al sureste de la ciudad (véase mapa 1), en la cuenca inferior del segundo. Era una extensión de pantanos y ciénagas que formaba parte de una llanura de leve pendiente nororiental que albergaba tierras muy fértiles, pero las cuales sin un buen sistema de escurrimiento se inutilizaban por el exceso de agua debido a las filtraciones níveas y las acumulaciones favorecidas por la inclinación del terreno (Prieto, Rojas, Castrillejo y Hernández, 2012). En efecto, el río Tunuyán nace en la cordillera de los Andes alimentado por las nevadas invernales, drenando un frente montañoso occidental de $110 \mathrm{~km}$ de longitud, con una cuenca de $18954 \mathrm{~km}^{2}$, para desembocar en el río Desaguadero, en el límite oriental de la actual provincia de Mendoza. El promedio histórico de su caudal es de $19 \mathrm{~m}^{3} / \mathrm{s}$, según los datos ofrecidos por el Departamento General de Irrigación en $2013,{ }^{6}$ aunque el curso original ya en el siglo $\mathrm{xx}$ fue afectado por la construcción del Dique Carrizal que regula hoy la distribución hídrica en la subcuenca inferior (Guirini, Médico y Vicchi, 2014, pp. 73-74), en la cual está ubicado el territorio en estudio, constituido por una extensión que disminuye en altura de 800 a $600 \mathrm{~m}$ de Oeste-Este, con escasas precipitaciones anuales (200 $\mathrm{mm}$ en promedio).

Un empadronamiento de fines de 1810 en Barriales contabilizó 353 habitantes, distribuidos en sólo 19 unidades censales, la mitad de ellas con una organización productiva orientada a la ganadería con capataces y mano de obra de peones y esclavos en propiedades de dueños ausentes. Incluía también "inquilinos-labradores", categoría que refería a una modalidad de arriendos de pequeños productores agrícolas que trabajaban con ayuda predominantemente familiar. En este territorio funcionaba la posta de Retamo, ubicada sobre el camino a Buenos Aires, unidad censal que conformaba un de-mendoza/

${ }^{6}$ Véase http://www.prensa.mendoza.gov.ar/irrigacion-informa-los-caudales-de-los-rios- 


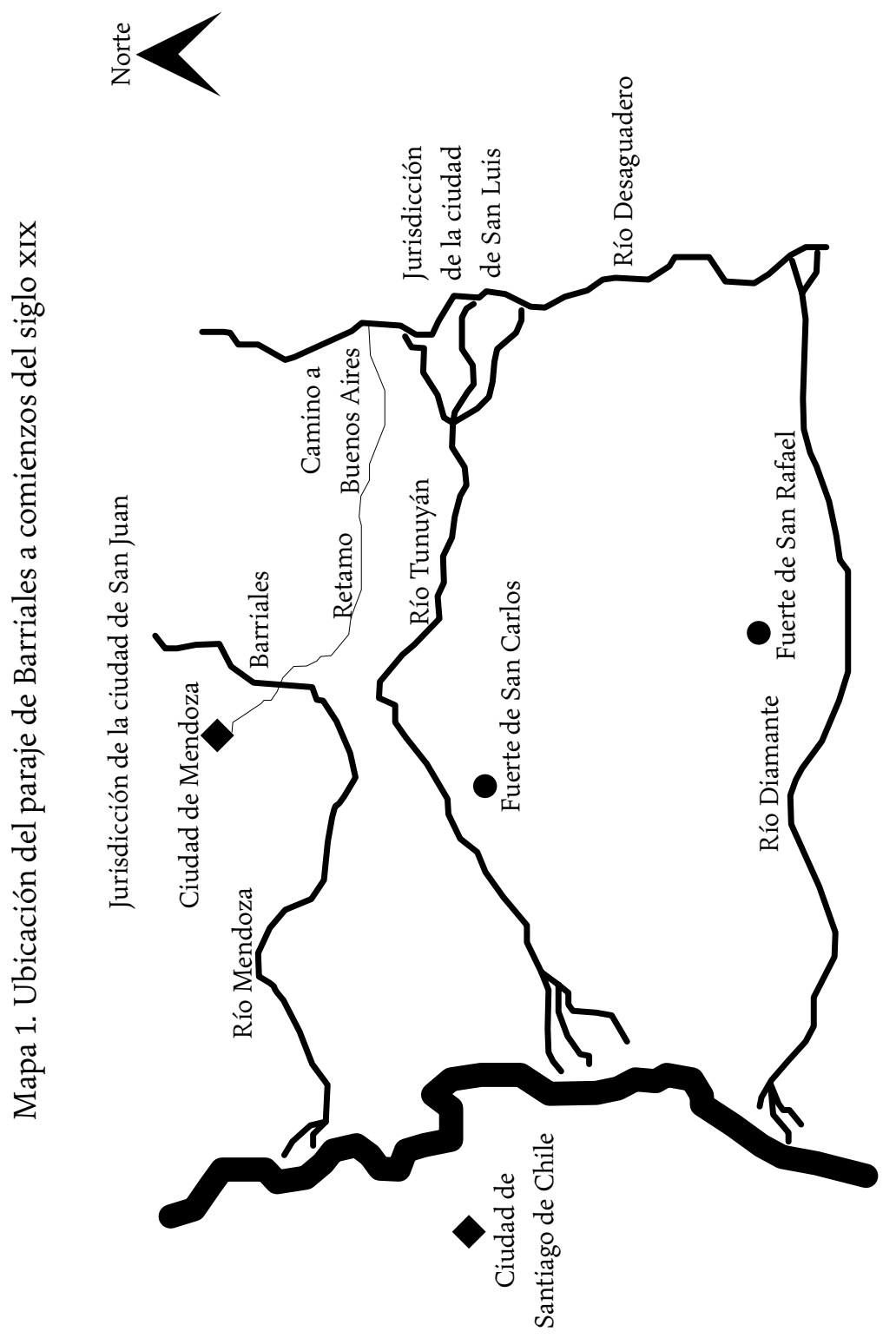

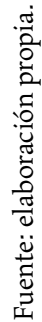


núcleo poblacional que en poco tiempo sería institucionalmente reconocido como tal debido a las 47 personas que ya aglutinaba por entonces (Molina, 2007, pp. 6-7).

Una política de poblamiento en ese territorio requería obras de desecamiento y reglamentaciones que evitaran que los desagües particulares agravaran los desbordes naturales producidos por la crecida del río en verano y las filtraciones subterráneas. Fue en el contexto de las urgencias logísticas revolucionarias cuando las autoridades comenzaron a prestarle atención. Al menos desde 1814, tanto Barriales como Retamo (poblado surgido en torno de la posta homónima) contaron con un decurión propio (Acevedo, 1979, p. 48), un juez menor que reunía funciones de justicia menor y policía equivalente a los alcaldes de barrio o pedáneos de otras jurisdicciones (Molina, 2007). En marzo de 1816 el gobernador San Martín envió una circular a estos últimos para que colaboraran con la obra de una acequia que llevaría agua desde el río Tunuyán, unas siete leguas hacia el norte (Draghi Lucero, 1941, p. 556). También comenzó la apertura de un camino que conectara a Barriales con la ciudad (pp. 558-559). Meses después se inició la venta de tierras públicas con el objetivo de ponerlas a producir: los particulares podían acceder a ellas por un monto de cuatro pesos la cuadra, ${ }^{7}$ con facilidades de pago, pero con el compromiso de sembrarlas (p. 555).

Mientras avanzaban las obras se multiplicaron los esfuerzos por interesar a potenciales propietarios (p. 557) y algunas solicitudes fueron rápidamente aprobadas. ${ }^{8}$ La voluntad de estimular pequeñas y medianas explotaciones era clara, ${ }^{9}$ como lo demostró San Martín al solicitar 50 cuadras para sí e intentar ceder las 200 que el Cabildo mendocino le había otorgado a su hija para fraccionarlas y premiar a los combatientes destacados de la próxima campaña a Chile (pp. 560-572). Siguiendo esta iniciativa, en mayo de 1817 envió los nombres de los agraciados y el tamaño de terreno que les corres-

${ }^{7}$ Una cuadra lineal tenía 126 metros según la proporción de 1 cuadra = 150 varas; 1 vara $=3$ pies; 1 pie = 0.28 metros (Martínez, 1961, p. 41; Garavaglia, 2011, p. 29). A partir de ello se calcula: 1 cuadra cuadrada $=1$ ha $5876 \mathrm{~m}^{2}$.

${ }^{8}$ Andrés Escalada al gobernador. 4 de julio de 1816. Correspondencia. Carpeta 239, doc. 41. Archivo General de la Provincia de Mendoza (en adelante AGPM), Argentina; José Pacheco al gobernador. 4 de julio de 1816. Correspondencia. Carpeta 239, doc. 42. AGPM, Argentina; Laurencio Silva al gobernador. 11 de mayo de 1816. Correspondencia. Carpeta 240, doc. 18. AGPM, Argentina.

${ }_{9}$ Los solicitantes denunciaban terrenos de 127 ha y 39 ha a 14 ha. 
pondía, los cuales oscilaron entre dos y seis cuadras. ${ }^{10}$ Tanto durante ese año como en los siguientes, las ventas y las concesiones continuaron para premiar el patriotismo y pagar las erogaciones impuestas a los vecinos (pp. 575-577).

Por entonces la gestión hídrica se regulaba allí a partir de una negociación de preeminencias comunitarias en la que la apelación a las referencias jurídicas indianas y su adaptación a las costumbres locales generaban interesantes tramas argumentales. Un ejemplo ilustrativo puede resultar un sugerente expediente iniciado en 1815.

En abril de ese año, Estanislao Pelliza se presentó ante el alcalde de primer voto denunciando que los colonos que ocupaban los terrenos de Clemente Godoy en los Barriales hacían casi imposible el riego de sus terrenos. ${ }^{11}$ Sostenía que el problema radicaba en el desorden con el cual abrían las tomas, enviando más agua de la que necesitaban a los Barriales y, por consiguiente, que faltara en los suyos. La solución que proponía era simple: colocar marcos como los de las acequias de la ciudad y también en las de otras ciudades rioplatenses (Doucet, 1983, p. 494; Martínez, 1970, p. 178), que servían para graduar el ingreso de agua a los predios según la proporción y calidad de los terrenos (esto es, si estaban o no labrados). No obstante, Godoy no creía que la cuestión fuera tan fácil, pues había una maraña de derechos de uso y servidumbres que impedían la salomónica propuesta de Pelliza.

En su contestación reconstruyó la historia de la acequia disputada para mostrar que él era su único propietario y, por tanto, no se le podía pedir minorar el uso del agua. Hacía varios años, cuando las tierras de Pelliza eran de otro dueño (José Porto y Mariño), ${ }^{12}$ había iniciado su delineación, trabajo en el que este último le pidió que lo incluyera para poder cultivar también el suyo, a lo

10 El gobernador Luzuriaga al Cabildo. 5 de mayo de 1817. Correspondencia. Carpeta 287, doc. 56. AGPM, Argentina.

${ }^{11}$ Estanislao Pelliza contra Clemente Godoy. Abril de 1815. Irrigación. Carpeta 100, doc. 11. AGPM, Argentina. Clemente Godoy era miembro conspicuo de la elite mendocina, lo que se evidencia en su participación en los cabildos abiertos clave de la revolución, su oficio en el cabildo y en la junta subalterna en 1811, siendo de los primeros propietarios de Barriales. Sin una actuación pública sostenida, Pelliza participó de los cabildos abiertos de 1810 y fue registrado en 1814 residiendo en la ciudad, sin precisar su ocupación, aunque sí era calificado como "don". Padrón cuartel 7. 1814. Censos. Carpeta 13, doc. 29. AGPM, Argentina.

${ }^{12}$ La propiedad era anotada a su nombre en Barriales en 1810, pero en el censo de 1814 fue registrado como residente de la ciudad. Razón de la gente encontrada en las Barrancas, costas del Tunuyán y Rodeo del Retamo. 17 de noviembre de 1810. Censos. Carpeta 13, doc. 2. AGPM, Argentina; Padrón de los individuos que habitan el cuartel núm. 4. 14 de febrero de 1814. Censos. Carpeta 13, doc. 11. AgPM, Argentina. 
que accedió pues como él estaría primero no le perjudicaría el acceso al agua. Según su relato, durante el primer año los resultados no fueron buenos porque el cauce se embarraba, y mientras su vecino, que no podía pagar tantos peones como él para reabrir el cauce, evaluaba vender o abandonar las tierras, Godoy contrató con un tercero el reacondicionamiento de la acequia, que esta vez fue exitoso. Así logró consolidar su propia labranza y la de Mariño, pero este autorizó a otro vecino contiguo a hacer uso de la acequia, quien cuando vendió en porciones su propiedad transfirió el acceso a tres nuevos usuarios. Incluso, otro labrador, en virtud de la servidumbre que le daba a la acequia un pequeño ángulo de sus tierras, había adquirido derecho a sus aguas. Con tantos regantes, decía Godoy, era lógico que se redujera el volumen de riego de Pelliza varios años después de adquirir la propiedad; sin embargo, sólo él poseía "derecho firme" por haber incurrido en los mayores gastos y esfuerzos para abrirla y conservarla, pues no se trataba de una acequia madre como alegaba su contendiente, sino una derivada de ella.

En los traslados cada parte insistió en su argumento, uno apuntando a la indisciplina de los inquilinos de Godoy como causante de la escasez de agua, y este remarcando sus derechos como hacedor y sostenedor de una acequia que los demás aprovechaban como intrusos. El asesor letrado propuso que las partes aceptaran un "practico imparcial" para inspeccionar los daños y arbitrar un acuerdo, tal como era común en el derecho de aguas indiano (Margadant, 1989, p. 139), pero Pelliza no aceptó y decidió presentar sus pruebas. Con sus testigos trató de mostrar el caos con el cual se abrían las tomas y su derecho a la mitad del agua porque su antecesor, Porto y Mariño, había corrido con la mitad del gasto en la apertura original de la acequia. Y agregó que el notable crecimiento de la labranza en los campos de su contendiente implicaba un mayor consumo de agua que perjudicaba al resto. Godoy insistió en que sólo él había pagado la apertura definitiva del curso litigioso y aportaba mayor cantidad de hombres y gastos para su conservación anual, cuando el deshielo montañoso exigía composturas para evitar derrames.

Los esfuerzos de Pelliza no lograron nada luego de un año de trámites judiciales, pero el expediente aporta varios elementos para analizar cómo se desarrollaba en Barriales por aquel entonces la gestión del agua. Primero que nada, era claro el papel de los decuriones en la trama de relaciones locales, pues precisamente tenían entre sus responsabilidades el mantenimiento de las acequias (limpieza, control de tomas, recomposición de derrumbes), y conviene recordar que para 1815 este paraje contaba con uno propio. Pero al 
parecer el arreglo de las aguas requería también que periódicamente se nombrasen comisionados para limpiar cauces, reconstruir paredes y controlar las tomas. En ambos casos era costumbre que fueran elegidos dentro de la comunidad y, aun, del conjunto de interesados de la acequia en cuestión, pues se suponía que sólo un conocimiento de las personas sobre las que se debía impartir justicia podía garantizar la equidad. Sin embargo, esta pertenencia comunitaria también podía convertirse en causa de parcialidad, ya que estos jueces debían seguir conviviendo y negociando con pares y subordinados luego de su gestión (Morelli, 2011). Eso es lo que evidencia la causa del análisis.

Juan de Dios Míguez, que era decurión cuando inició la causa, fue citado como testigo por Pelliza y presentó un informe confirmando el desorden de los inquilinos. Mateo Godoy, quien había ejercido el cargo en 1814, testimonió en el mismo sentido. Los dos tenían una corta residencia en Barriales, ${ }^{13}$ como Pelliza, pero los vínculos entre ellos eran más o menos sólidos. Míguez era juez y parte pues constituía uno de los propietarios que se había beneficiado del permiso original de Mariño sobre la acequia y, por tanto, era uno de los perjudicados por la escasez del riego. El otro decurión había tenido enfrentamientos con los colonos de Clemente Godoy, amenazándolos con multas por los tapones que ponían para interrumpir el curso, provocando derrames. Ninguno fue citado por este último, estrategia que demuestra cómo conocía las parcialidades que estimulaban los vínculos comunitarios dentro del escenario judicial (Garavaglia, 1999).

La causa da cuenta también de la intervención de los comisionados para recomponer la acequia, que también implicaba el ejercicio de jurisdicción en tanto su acción podía afectar los intereses de los pobladores (Garriga, 2004; Mannori, 2007). Los testigos confirmaron la intervención de un encargado de la limpieza, intentando precisar si se trató de un comisionado o un peón particular. Definir quién le había ordenado su actuación implicaba establecer si había habido capacidad jurisdiccional y que la resistencia a ella presentaba otro tenor. El sujeto designado se autodefinió como comisionado pero otros sostuvieron que no sabían "quién lo mandó” y si había arreglado el cauce, no podían decir "por qué orden".

13 Míguez había comprado tierras allí en 1815 (Draghi Lucero, 1941, p. 554) y Mateo Godoy declaró ser vecino de Barriales desde hacía dos años, cuando era decurión en 1814. Ninguno fue registrado en 1810. Razón de la gente encontrada en las Barrancas, costas del Tunuyán y Rodeo del Retamo. 17 de noviembre de 1810. Censos. Carpeta 13, doc. 2. AGPM, Argentina. 
Otro aspecto evidenciado es cómo el estricto control sobre acequias madres y derivadas que se daba en la ciudad (Sanjurjo, 2011) aquí era reemplazado por una negociación de vínculos comunitarios y preeminencias simbólicas. Si era obvio que el agua era común y todos podían acceder a ella según sus necesidades (Margadant, 1989, p. 124), la construcción de cauces artificiales generaba derechos a quienes invertían en ellos, sobre todo cuando atravesaba terrenos propios. De hecho, el dictamen final se asentó en este principio: como Pelliza no podía demostrar que su antecesor hubiera colaborado con la mitad de la edificación de la acequia no podía alegar igualdad de dominio.

Pero había otro problema: la proporcionalidad entre tierras cultivadas y agua, la cual generaba conflictos al avanzar la labranza, pues era claro que debía haber proporcionalidad en la distribución del agua teniendo en cuenta el tamaño y calidad de los terrenos, tal como era común en otras jurisdicciones rioplatenses (Vives, 1990, p. 487). Pelliza afirmaba que el aumento de las cuadras cultivadas por los inquilinos de Godoy era una de las causantes de la escasez, por lo que pedía marcos que fijaran una cuota hídrica según los terrenos labrados en ese momento. Ahora, ise podía frenar el crecimiento agrícola siguiendo el principio distributivo por el cual no se podía favorecer a uno perjudicando a muchos teniendo en cuenta que el interés individual debía ceder ante el comunal, y el de los grupos pequeños ante el general? (Margadant, 1989, p. 144) Parecía que no. Los testigos coincidieron en que el desarrollo productivo de las tierras de Godoy era consecuencia del éxito de su reapertura del cauce, lo que evidenciaba, quizá sin quererlo Pelliza, las buenas consecuencias de ello. Y la defensa de Godoy se asentó en que explotaba sus tierras a través de inquilinos o colonos, ${ }^{14}$ régimen que habilitaba el asentamiento y el trabajo de subalternos, con los beneficios comunitarios que tenía un morador con casa poblada y oficio útil a los ojos gubernamentales (Barral, Fradkin y Perri, 2007).

La estrategia judicial de Pelliza no llegó a buen puerto, pues el juzgado dictó no innovar, evidenciando que en las decisiones sobre aguas prevalecía una flexibilidad casuística más que un rigor legalista (Sanjurjo, 2011). Para entonces, sin embargo, las ya referidas obras públicas (canal y camino) emprendidas por el gobierno, sumado al estímulo de la venta de tierras con el objeto

${ }^{14}$ Es probable que el término y la práctica tuviera conexión con el inquilinato del valle central chileno (Salazar, 2000), dada la presencia en Barriales de naturales de allende Los Andes. En la causa, de diez testigos, cinco eran nacidos en Chile; también lo era José Herrera, propietario y constructor de la acequia pública principal. 
de ponerlas en cultivo, fueron acompañados por un marco institucional para ordenar las prácticas y arbitrar tanto los conflictos comunitarios debidos al aprovechamiento del agua que se ha visto en la causa judicial analizada, como los efectos que la abundancia de ella generaba por las características geomorfológicas también mencionadas.

\section{ENSAYOS REGLAMENTARIOS PARA UN NUEVO ESPACIO POLÍTICO}

\section{Ajustando clavijas en la gestión hídrica dentro del marco de los vínculos comunitarios}

En 1819 el gobernador Luzuriaga otorgó al comisionado Pedro Regalado de la Plaza amplia jurisdicción para dar forma a las nuevas poblaciones, otorgándole capacidad para nombrar tenientes, impartirles instrucciones y dictar justicia en materia de aguas. ${ }^{15} \mathrm{El}$ "Reglamento probisional que debe observarse en las nuevas Poblaciones de Barriales" que el comisionado presentó, da cuenta de la densidad de las articulaciones comunitarias entre agua y justicia en la gobernabilidad de este territorio. ${ }^{16}$ Delineaba un espacio político sobre el que se aplicarían normas, delitos y castigos específicos, no extensivos a otros territorios de la campaña mendocina. Creaba una organización nueva sobre la jurisdicción de los dos decuriones existentes. Los nuevos oficios que disponía estaban vinculados con la conservación de la acequia pública principal y las derivaciones que se hiciesen: un tomero para regular la apertura y conservación de tomas, pagado por los vecinos; dos tenientes que tendrían a su cuidado la observancia de la normativa en cada una de las dos mitades en las que se partía la citada acequia, y dos peones a su disposición (también asalariados por los propietarios) para contener derrumbes y estancamientos. Estos tenientes podían imponer castigos pecuniarios y penas de encierro, aunque De la Plaza se reservó el lugar de mayor jerarquía en la trama jurisdiccional,

${ }^{15}$ El gobernador Luzuriaga a Pedro Regalado de la Plaza. 2 de abril de 1819. Antecedentes de las villas. Carpeta 1, doc. 6. AGPM, Argentina. Sanjurjo (2004, pp. 33-35) ha llamado la atención sobre la continuidad indiana en materia de acumulación de funciones (judiciales, policiales) en estos comisionados para el poblamiento de la campaña mendocina.

${ }^{16}$ Pedro Regalado de la Plaza al gobernador Luzuriaga. 10 de abril de 1819. Antecedentes de las villas. Carpeta 1, doc. 6. AGPM, Argentina. 
ya que a él debían acudir los vecinos ante conflictos, atribuyéndose arbitrio punitivo "conforme a la calidad y circunstancia del delito".

En este nuevo espacio político que buscaba diseñarse se comprometía a los vecinos en el mantenimiento de los cursos de agua. Todos pagaban el tomero y los peones que colaboraban con los tenientes, obligándose a entregar auxilios cuando la situación lo requiriese, mantener los bordes de las acequias a igual altura, informar la cantidad de tierras sembradas para definir la suerte de agua correspondiente, evitar plantar árboles que no fueran álamos en las orillas y no llevar sus rebaños a beber allí. No se trataba sólo de integrarlos en una responsabilidad común sino también de cimentar su arraigo, pues el prorrateo de los gastos y la distribución de agua requerían un conocimiento exacto de los residentes. Así, aun cuando se vendiesen terrenos a un hermano, la parte que enajenaba debía dar cuenta de la transacción para reglar la cuota de derrames, lo que muestra cómo el margen de acción que mostró el expediente judicial de 1815 se reducía, al menos en el papel.

Había otro elemento que daba particularidad a este nuevo espacio político sobre el cual se desplegaba esta inédita voluntad de ordenamiento y control si se la compara con el resto de la jurisdicción de Mendoza: el que se hubiera destinado allí a un grupo de prisioneros de la campaña a Chile (Masini Calderón, 1979, p. 143). El reglamento establecía la prohibición de que pudiesen conchabarse entre los vecinos y andar a caballo, especificando que debían dormir en la guardia; no obstante, no sólo trabajaron para el gobierno, sino que fueron distribuidos entre vecinos, e incluso lograron pasar como peones libres.

Es claro que la normativa buscaba ordenar una trama comunitaria de derechos de agua y accesos a la tierra que aquí se regulaba hasta entonces a partir de la costumbre, las preeminencias negociadas según los tiempos de residencia y el capital simbólico de cada vecino, como evidenció el expediente de 1815. Aquella recogía prácticas de control hídrico ya arraigadas en el ámbito urbano de Mendoza, pero que eran ajenas aquí, pero a su vez le agregaba elementos surgidos de la propia experiencia comunitaria local. Así, miniaturizaba el espacio a controlar al dividir por mitades la acequia pública para garantizar un control más minucioso, haciendo que la red judicial conformada por De la Plaza y sus tenientes se articulara con la de los dos decuriones con los que contaban Retamo y Barriales desde 1814. Lo que para estos pobladores resultaba novedoso, tal como era el control sobre el tamaño de las propiedades para distribuir proporcionalmente la cuota de prorrata de 
la acequia, conformaba una larga tradición en los barrios cercanos al casco urbano, mientras que sí era muy particular la disposición de mano de obra regular para enfrentar las vicisitudes provocadas por las crecidas estacionales a partir de los peones previstos para ayudar a los tenientes.

Que la reglamentación entró en vigencia queda demostrado en una causa judicial en la cual aparecieron en escena las figuras establecidas por ella. Allí, uno de los flamantes tenientes fue denunciado por haber protegido a un prisionero que, instado por el otro teniente para colaborar en la contención de un derrumbe, se había negado, insultando a las autoridades. El proceso judicial da cuenta del papel clave del comisionado De la Plaza en la recolección de testimonios, la efectiva capacidad correctiva de los tenientes sobre quienes se negaban a cumplir sus solicitudes operativas respecto de las acequias y la eficiente dinámica que preveía la norma para garantizar cauces regulares. ${ }^{17}$ No existen datos para saber qué ocurrió en los años siguientes; pues recién se dispone de ellos para 1823, cuando se decidió la planeación definitiva de la Villa Nueva de San Martín como centro político que integrara en un espacio a Barriales y Retamo.

En 1821, la Sala de Representantes ${ }^{18}$ dispuso la elección de un subdelegado que se ocupase allí de la justicia civil de primera instancia y, desde esa época al menos (pues no hay referencias previas), el juez de aguas fue elegido por los propios vecinos. Así, hasta ese momento el Cabildo había sido el encargado de cuidar la gestión hídrica nombrando alcaldes o jueces comisionados al efecto, cuando en algunas jurisdicciones indianas eran las comunidades de riego espontáneas, formadas por propietarios, las que elegían a estos (Margadant, 1989, pp. 119-120). El caso mendocino da cuenta de la influencia directa de las prácticas introducidas por la revolución en la vida política de la ciudad, pues en diversos canales la selección de los jueces fue realizada por la comunidad de vecinos luego de 1820 , siempre notificando el resultado de los comicios a las autoridades superiores. ${ }^{19}$ En el emergente cuadro político

${ }_{17}$ Causa contra José Salomón por injurias al gobierno. 20 de septiembre de 1819. Judicial criminal. Carpeta S-1, doc. 27. AgPM, Argentina.

${ }^{18}$ En 1820 las tres ciudades que formaban la Intendencia de Cuyo se desvincularon e iniciaron procesos de configuración republicano-representativa. Como parte de este se formó la Sala de Representantes.

${ }^{19}$ Acta de elección de inspector de agua de la hijuela de Allaime y Tajamar. 18 de julio de 1822. Irrigación. Carpeta 100, doc. 24. AGPM, Argentina; Juan de Dios Míguez al gobierno. 9 de junio de 1823. Irrigación. Carpeta 100, doc. 29. AGPM, Argentina. 
configurado en torno de la Villa Nueva de San Martín, también los regantes seleccionaban entre ellos al que creyeran más conveniente, o al que pudiera movilizar mejor sus relaciones personales al momento de la elección, lo que reflejaba la integración de sus miembros en los vínculos comunitarios.

En efecto, en la citada elección de 1823 el nominado fue José Herrera, residente desde comienzos del siglo xix y constructor de la acequia pública contratada por el gobierno en 1815, pero también recibieron sufragios Juan Jurado y José Orozco, ambos propietarios recientes (Draghi Lucero, 1941, pp. 554-555). Esta reunión de vecinos y el citado expediente de 1815 muestran cuánto lograba vincularlos la gestión del agua, pues los nombres se repetían una y otra vez, tal como mostró la compulsa de los expedientes que se analizarán más adelante en el apartado titulado "Comunidad de regantes, gobierno provincial y conflictividad hídrica”.

\section{Ejercicios normativos posteriores \\ a la desaparición del Cabildo}

En 1825 la desaparición del Cabildo aceleró una serie de reformas institucionales que venían ensayándose en los años anteriores, las cuales implicaron junto al fortalecimiento de la Sala de Representantes, la incipiente organización de una justicia de primera instancia con su tribunal de alzada y la fijación del rubro de policía dentro de la esfera del poder ejecutivo. Como parte de este esfuerzo organizacional para reemplazar el orden capitular extinguido, el Reglamento de Policía de 1828, los Reglamentos de Estancias y Justicia de 1834 y otro de Estancias de 1845, apuntaron a precisar en el territorio las funciones del nuevo diseño político para toda la provincia de Mendoza. Los espacios periféricos intentaban ser controlados por el gobierno central a través de dispositivos en los que la clave era la relación directa y personal entre población y autoridades, continuando con las modalidades de la justicia de proximidad del periodo tardocolonial (Molina, 2015). Como consecuencia de ese corpus normativo, y atendiendo al crecimiento demográfico y el desarrollo productivo aparejado, se dividió la campaña en departamentos, a cuya cabeza se establecieron subdelegados con funciones de justicia, policía y fiscalidad. Por debajo de estos funcionarios, se confirmaron a comisarios y decuriones, con funciones similares, subordinados a los primeros (Sanjurjo, 2004, pp. 4356). Respecto de la gestión del agua también hubo desplazamientos jurisdic- 
cionales, pues si en el periodo colonial la merced de agua se consideraba "un derecho real, transferible y transmisible, normalmente de carácter perpetuo, que otorga la corona respecto de aguas corrientes, detenidas o vertientes, superficiales o subterráneas" (Dougnac Rodríguez, 1984, p. 53), convirtiéndose en públicas al ser esa atribución cedida a los cabildos y las villas, ese poder de otorgarla pasó a los gobiernos provinciales formados en el Río de la Plata luego de 1820 (véase organigrama 1).

En torno de la Villa Nueva de San Martín se delineó el departamento homónimo, también denominado $7^{\circ}$, que comenzó a adquirir una relevancia clave en la logística provincial por la disponibilidad de animales de transporte y comida que se criaban en los potreros públicos y privados que allí se multiplicaban. Como lo estipulaba la citada reglamentación, contaba con un subdelegado, un comisario y al menos dos decuriones, trama de autoridades que intentaban gobernar un notable desarrollo productivo, conectado a la residencia fija de un conjunto de moradores y vecinos dedicados al cultivo forrajero. Esto en un contexto de creciente consolidación de un modelo de ganadería comercial con agricultura subordinada que desplazaba la actividad vitícola que caracterizó a la economía local hasta entonces (Richard Jorba, 1998), y de un aumento demográfico continuo que se observa al comparar, respecto de Barriales, los 353 habitantes del empadronamiento de 1810 referido al comienzo del trabajo, con los 8862 contabilizados para 1855 (Sanjurjo, 2004, p. 190) o los 9503 registrados por Martín de Moussy en 1857 (Masini Calderón, 1979, p. 151).

En ese marco de expansión de las tierras labradas (evidenciada en los caracteres de los terrenos mencionados en los protocolos de compraventa y en las fuentes de gobierno, aunque no existen estudios sistemáticos sobre la frontera agrícola para el periodo y el territorio), se sancionó un decreto específico para reglamentar el ramo de aguas en la Villa, en enero de 1837 (Cano, 1941, pp. 215-217). El foco disciplinar seguía estando en el riego y la acequia principal, aquella que había comenzado José Herrera en 1815, la cual se presentaba como columna vertebral del poblado y primordial ocupación de autoridades, vecinos y el juez principal de aguas. De ese canal se preveía la derivación de cuatro nuevas acequias perpendiculares con orientación hacia el este (Alto Verde, de la Villa, del Medio y Alto de las Mulas). Sin embargo, su construcción no se haría por cupo como tradicionalmente, aportando cada propietario la cantidad de peones según el tamaño de sus posesiones, sino siguiendo la delineación de cada una, de forma que empezando todos en la 


\section{Organigrama 1. Autoridades según \\ Reglamentos de 1828,1834 y 1845}

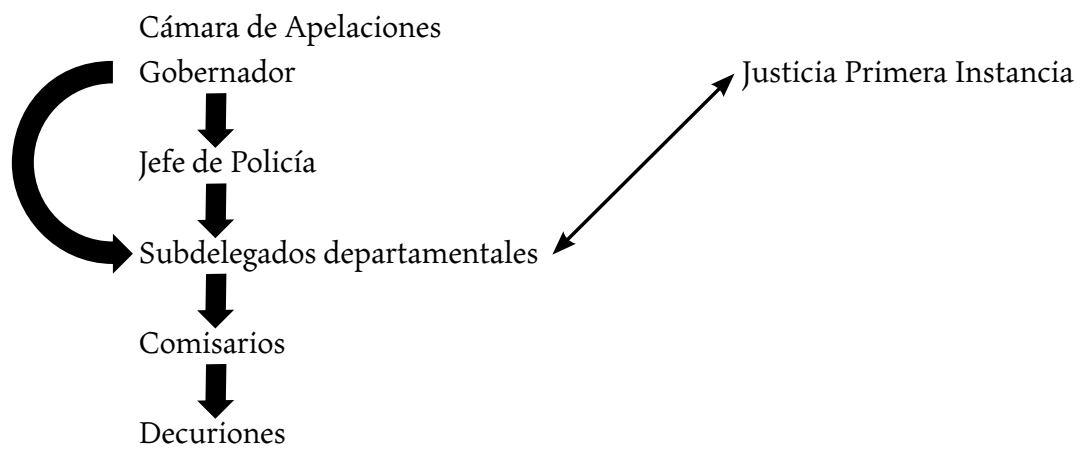

Fuente: elaboración propia.

acequia madre, trabajarían hasta llegar a la altura de sus tierras. Esta práctica distinta de la acostumbrada (tal como era referida en el expediente citado de 1815), podría estar mostrando la mayor injerencia de un gobierno que individualizaba propiedades y propietarios con creciente precisión, como parte de un esfuerzo normativo más amplio que apuntaba a estructurar el orden político del naciente estado provincial.

De hecho, si se repetían prohibiciones viejas en una jurisdicción acostumbrada a cuidar el agua como oro, como la de abrir tomas sin autorización judicial, y en caso de solicitarla requerir la intervención del juez de aguas con dos vecinos que a "vista de ojos" la concederían, o la de imponer parapetos que causaran derrumbes o inundaciones, también se evidenciaba mayor racionalidad en la administración de los desagües. Si antes se regulaban según la costumbre y la dinámica de las relaciones comunitarias en cada acequia e hijuela, ahora se preveía un sistema ordenado hacia la acequia contigua, facilitado por la pendiente natural del terreno ya referida.

También se ocupaba de la convivencia cotidiana, exigiendo al comisario la refacción de las calles para evitar disputas entre vecinos y al subdelegado el control de la movilidad de la población, sobre todo de la que no tenía ocupación, para expulsarla o enviarla a la ciudad para ser remitida a la frontera sur. Ambas medidas apuntaban a fortalecer la trama de vínculos y conceptualizaban como riesgo cualquier elemento que no se acomodase a la noción 
de "vecino laborioso" difundida por el gobierno, la que tenía en este departamento en particular una excelente aplicación (Sanjurjo, 2004, pp. 68-72).

Una nueva normativa sobre acequias siguió ajustando clavijas en un contexto provincial de creciente voluntad ordenadora, acorde con los inicios del proceso constituyente nacional y local que culminaría con la sanción de las Constituciones de 1853 y 1854, respectivamente. En efecto, en 1852 se sancionó el Reglamento para el Régimen Administrativo del Canal Principal de El Retamo (Cano, 1941, pp. 238-244), que detallaba cómo se iba a abrir, sostener y conservar una acequia matriz que debía regar los campos de este sector del departamento. Y si bien nuevamente repetía fórmulas y estrategias conocidas, conviene prestar atención sobre algunas que no lo eran tanto. Primero: la normativa surgió de una comisión elegida por una reunión de vecinos que, presidida por autoridades centrales de la provincia, no dejaba de mostrar una comunidad de propietarios en acción. De hecho, el artículo inicial establecía que cada año elegirían a un juez de la acequia (como se hacía desde 1823), pudiendo reelegirse por sólo una vez, lo que garantizaba que el cargo rotase entre los interesados. La intervención no quedaba en ese ejercicio temporario de la justicia sino que se aseguraba a través de otras actuaciones: la participación de al menos cuatro propietarios nombrados por el vecindario junto al juez en los acuerdos con tomeros y subastadores del río; la selección de un recaudador; la opinión con voto activo en la inversión que debía darse a los fondos comunes obtenidos de la prorrata y las multas, como también en el control de juez y recaudador, quienes al terminar su periodo debían informar entradas, gastos y remanentes de la caja de la acequia. Incluso, el juez requería de la anuencia de los interesados para conceder nuevas tomas en la matriz o las hijuelas. En tal sentido, la vigencia de los criterios del paradigma jurisdiccional parecía intacta, pues si el juez de la acequia podía utilizar medios de coerción propios del ejercicio de jurisdicción (multas, arrestos o privación del riego), no podía dejar a las partes interesadas sin el recurso de apelar a una autoridad superior, por lo cual por sí solo no estaba habilitado a privar de tomas, imponer servidumbres ni suspender las vigentes.

Tampoco parecía novedoso el registro actualizado que el recaudador debía llevar para distribuir equitativamente los gastos del canal, aunque sí tenía un acento sistematizador inédito, a tono con los esfuerzos burocratizadores en otros aspectos de la gestión de los departamentos tal como la insistencia central en la formación, conservación y transferencia de los archivos administrativos (Molina, 2017). Se precisaba que debía tener un libro con los 
terrenos labrados y sin labrar de cada propietario, para cuya elaboración el juez anualmente debía pedir informe a los vecinos, y en caso de información falsa los multaría. La minuciosidad en el registro de tierras y de su calidad apuntaba a ordenar un desarrollo agrícola que había comenzado a generar problemas comunitarios crecientes. El problema planteado por Pelliza en 1815 era asumido dentro de la comunidad de regantes. Así, lo que en esa fecha no había resultado clave para justificar una sentencia, se normaba ahora con precisión: cada ampliación de cultivos debía ser anualmente declarada y el riego sería acordado por el conjunto de interesados. La normativa estimulaba prácticas comunitarias de gestión en las cuales, si bien el control gubernamental estaba presente, creaba un ámbito regulado para la participación de los usuarios (siempre propietarios, conviene remarcarlo).

\section{COMUNIDAD DE REGANTES, GOBIERNO PROVINCIAL Y CONFLICTIVIDAD HÍDRICA}

¿Qué dice la judicialidad de esta actuación comunitaria en la gestión del riego? Según la documentación compulsada se aprecia un dato llamativo: mientras que en el periodo extendido entre la revolución y el Reglamento de 1837 sólo se detectaron dos causas por conflictos hídricos, durante las dos décadas siguientes se registraron 20 expedientes. Esta disparidad numérica pudo tener que ver básicamente con la falta de conservación archivística, pero caben quizá otras hipótesis. Una podría ser que la consolidación de las políticas de organización y transferencia de los archivos públicos, en general, y de aguas, en particular, se hubiesen consolidado, tanto a partir de los requerimientos reglamentarios (Ahumada, 1860, pp. 88 y 94) cuanto por el disciplinamiento de los subdelegados a nivel departamental y de los tribunales de primera instancia a nivel provincial. ${ }^{20}$ Ellas parecieron fortalecer las cadenas de intervención judicial estipuladas por el Reglamento de Aguas provincial de 1844, a las cuales autoridades y población se habituaron progresivamente. Así, puede no ser casual que las 20 causas encontradas fueran posteriores a 1848 , y que si

${ }^{20}$ La notificación al gobierno del subdelegado de aguas de San Martín en 1858 da cuenta de la preocupación por la conservación de los archivos. El subdelegado interino de la Villa de San Martín al ministro de Gobierno. 24 de marzo de 1858. Irrigación. Carpeta 105, doc. 12. AGPM, Argentina. 
hasta 1852 sólo se realizaron (o conservaron) seis, entre 1852 y 1859 fueron diez. Junto al aumento de la litigiosidad se observa un aceitado procedimiento de instancias de solicitud y resolución dentro de la escalera judicial de aguas. De hecho, entre julio y agosto de 1856 un par de oficios entre el juez de aguas departamental, el juzgado general y la gobernación, revelaban la necesidad de que la primera contara con un escribiente por las "muchas atenciones de su ramo", y que se nombrase para lo amplio de su jurisdicción dos subtenientes que vigilasen el cumplimiento de las reglamentaciones. También los pedidos de papel, libros y utensilios de oficina revelan una burocracia creciente en la judicialidad de aguas. ${ }^{21}$

En efecto, los expedientes muestran cómo los vecinos del departamento seguían lo pautado por la normativa provincial de 1844: elevaban sus pedidos al juez general de aguas (con jurisdicción ordinaria en asuntos de más de 50 pesos y dictamen del asesor letrado) (Cano, 1941, p. 220); este solicitaba informe al juez del ramo departamental y este al de la acequia respectiva si el caso versaba sobre apertura, traslado o perjuicios producidos por una toma. La práctica tradicional de "vista de ojos" se conservó, realizada por una comisión nombrada por el juez general provincial y encabezada por el juez departamental o el de la acequia con dos o tres vecinos interesados del canal. ${ }^{22}$ Pero hubo ocasiones en las que con solamente la opinión de alguno de esos jueces locales dictaminó el provincial, aunque hay que recordar que estos emitían sus consideraciones como conocedores de la trama comunitaria, los rasgos del terreno y la dinámica estacional de los cursos de agua, como afirmaba el juez general de aguas al solicitar un informe al departamental para conocer "las aguas practicas y costumbres" del lugar en cuestión..$^{23}$ Una vez concluido y presentado el informe el juez general decidía y notificaba a sus subordinados para su ejecución (véase organigrama 2).

La transferencia de los procesos al gobernador se realizaba para casos específicos, como la autorización para establecer molinos, por ser de utilidad

${ }^{21}$ El juez general de aguas al gobierno. 29 de julio, 1 de agosto y 4 de agosto de 1856 . Irrigación. Carpeta 104, doc. 7, 9 y 11. AGPM, Argentina.

22 Nazario Ferreyra solicita se le dé permiso para sacar una acequia. 2 de octubre de 1848. Irrigación. Carpeta 101, doc. 41. AGPM, Argentina; Vicente Gil sobre rehabilitación de una toma. 19 de febrero de 1851. Irrigación. Carpeta 101, doc. 53. AGPM, Argentina; Piden participar de las aguas de la acequia de Chilecito para regar sus tierras. 27 de septiembre de 1851 . Irrigación. Carpeta 101, doc. 57. AGPM, Argentina.

${ }^{23}$ Ventura Videla solicita agua para sus terrenos. 20 de febrero de 1855. Irrigación. Carpeta 103, doc. 29. AGPM, Argentina. 


\section{Organigrama 2. Instancias judiciales luego de la Ley Provincial de 1844}

Juez general provincial de aguas

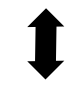

Juez subdelegado de aguas departamental

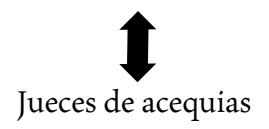

Fuente: elaboración propia.

pública, esto es, de decisión gubernamental superior, ${ }^{24}$ pero también aquí la opinión de los regantes afectados era clave.

Los criterios que rigieron durante estos años parecían seguir siendo los de la cultura jurídica indiana: el agua era un bien común (Dougnac Rodríguez, 1984 , pp. 51-52; 1985, p. 283) y no podía negársele al que la necesita$\mathrm{ba},{ }^{25}$ los derechos de uso antiguos eran preferibles a los nuevos (Margadant, 1989, p. 140), ${ }^{26}$ una concesión debía respetar el interés público y el de tercero, ${ }^{27}$ la inspección ocular conformaba la base de cualquier decisión judicial, ${ }^{28}$ la aceptación de servidumbres de acequias ajenas en las tierras propias otorga-

${ }^{24}$ Guillermo Cano solicita permiso para construir un molino. 9 de junio de 1849. Irrigación. Carpeta 101, doc. 43. AGPM, Argentina; Pedro Charles pide permiso para construir un molino en la acequia de Alto Verde. 23 de setiembre de 1852. Irrigación. Carpeta 102, doc. 14. AGPM, Argentina.

${ }^{25}$ Ventura Videla solicita agua para sus terrenos. 20 de febrero de 1855. Irrigación. Carpeta 103, doc. 29. AGPM, Argentina; Piden participar de las aguas de la acequia de Chilecito para regar sus tierras. 27 de septiembre de 1851. Irrigación. Carpeta 101, doc. 57. AGPM, Argentina.

${ }^{26}$ Vicente Gil sobre rehabilitación de una toma en las costas del Tunuyán. 19 de febrero de 1851. Irrigación. Carpeta 101, doc. 53. AGPM, Argentina; Piden participar de las aguas de la acequia de Chilecito para regar sus tierras. 27 de septiembre de 1851. Irrigación. Carpeta 101, doc. 57. AgPM, Argentian; Rafael Ayroldi solicita merced de aguas. 10 de diciembre de 1854. Irrigación. Carpeta 103, doc. 44. AGPM, Argentina.

${ }^{27}$ Vicente Gil sobre rehabilitación de una toma en las costas del Tunuyán. 19 de febrero de 1851. Irrigación. Carpeta101, doc. 53. AGPM, Argentina; Matías Godoy por una toma en el río Tunuyán. 12 de enero de 1856. Irrigación. Carpeta 103, doc. 46. AGPM, Argentina.

${ }^{28}$ Vicente Gil sobre rehabilitación de una toma en las costas del Tunuyán. 19 de febrero de 1851. Irrigación. Carpeta 101, doc. 53. AGPM, Argentina. 
ba derecho al agua que por ella corría ${ }^{29}$ y el beneplácito de la comunidad de regantes era básico para que las autoridades concediesen autorizaciones para abrir nuevas tomas en el río o canales públicos. ${ }^{30}$ Sin embargo, se detectan dos cuestiones. Por una parte, la incorporación de un ingrediente monetario que no sólo tenía que ver con la prorrata que distribuyera proporcionalmente los gastos de su mantenimiento; en efecto, el concepto de venta o pago de derechos de uso o de servidumbre fue solicitada o requerida en ciertas ocasiones, ${ }^{31}$ mientras que en las décadas anteriores esto implicaba un acuerdo verbal de las partes sin información a ninguna instancia judicial, con el compromiso de que el nuevo regante cumpliera con las obligaciones comunes. ${ }^{32}$ Llama la atención esta práctica porque no ha sido verificada antes en esta jurisdicción, pues el vínculo entre tierras y aguas parecía ineludible, mientras sí era habitual en la gestión hídrica de otras comunidades españolas, como Alicante, en donde se configuró un mercado de derechos de agua vigente hasta el siglo xx (Garrido, 2011, pp. 20 y 24; Calatayud, 2016, pp. 26-27) aun cuando la reglamentación general consolidó a fines del siglo xIx el criterio de que el uso del agua era inseparable de la tierra, y el carácter no mercantil de la primera (Calatayud, 2016, p. 25).

Por otra parte, se observa quizá un mayor peso decisorio del gobierno en la gestión del recurso, pues si la citación y consulta a los vecinos interesados siguió siendo un paso ineludible del proceso administrativo previo al dictamen del juez departamental o general, e incluso, una solicitud de derecho que contara con el previo aval de los regantes prometía superar con mayor éxito y celeridad el trámite judicial, ${ }^{33}$ en ocasiones también se constató que la decisión gubernamental no respetó el sentir de los afectados. ${ }^{34}$ En ello, si el argumento seguía basándose en que el interés común era más relevante que

${ }^{29}$ Piden participar de las aguas de la acequia de Chilecito para regar sus tierras. 27 de septiembre de 1851. Irrigación. Carpeta 101, doc. 57. AGPM.

${ }^{30}$ Matías Godoy por una toma en el río Tunuyán. 12 de enero de 1856. Irrigación. Carpeta 103, doc. 46. AGPM, Argentina.

${ }^{31}$ Doña Luciana Gómez de Alanis solicita se le dé derecho a agua para regar sus terrenos en Alto de las Mulas. 24 de abril de 1849. Irrigación. Carpeta 101, doc. 42. AGPM, Argentina.

${ }^{32}$ Nazario Ferreyra solicita se le dé permiso para sacar una acequia del río Tunuyán. 2 de octubre de 1848. Irrigación. Carpeta 101, doc. 41. AGPM, Argentina.

${ }^{33}$ Felipe Zorraindo solicita agua para terrenos en San Martín. 11 de setiembre de 1855. Carpeta 103, doc. 35. AGPM, Argentina; Ventura Videla solicita agua para sus terrenos. 20 de febrero de 1855. Irrigación. Carpeta 103, doc. 29. AGPM, Argentina.

${ }^{34}$ Faustina Núñez se le ponga en posesión de su derecho de agua concedido por el juzgado. 7 de febrero de 1853. Irrigación. Carpeta 102, doc. 23. AGPM, Argentina. 
el particular, resulta interesante que se apoyara sobre una dinámica judicial cada vez más aceitada en su cadena de mando. En este sentido, una orden de ejecución de sentencia de 1855 del juzgado general al departamental se refería a actuar "en la forma de costumbre", lo que refleja la cimentación de jerarquías y subordinaciones, aunque no implicaba automática obediencia, sobre todo por los jueces de acequias, cuyos intereses formaban parte del vecindario sobre el que ejercían su jurisdicción. ${ }^{35}$ No obstante, si la decisión pública iba en contra de las opiniones particulares en cierto momento del proceso, la regla implicó una estrategia de negociación para obtener el beneplácito de aquellas. ${ }^{36}$

Así, los pobladores siguieron teniendo un papel clave en la gestión del recurso, pues no sólo eran convocados durante las inspecciones oculares y se tramitaba forzadamente su parecer, sino que conservaron su papel como electores de los jueces de acequias. ${ }^{37}$ No obstante, la intervención gubernamental fue creciendo. Ello se expresó en la consolidación de los circuitos administrativos vinculados a la solicitud y control en el uso del agua que se ha referido, en dictámenes que se opusieron al parecer del vecindario afectado aun cuando se lo tratara de convencer después, como también en la legitimidad que daba el aval del juez provincial en materias que antes se resolvían extra judicialmente. Así, en 1855 un vecino que venía haciendo uso del derecho concedido por la comunidad y el juez de su acequia se presentó de todos modos ante aquel para confirmar su derecho. ${ }^{38} \mathrm{Y}$ hasta el mismo acuerdo previo de la comunidad de regantes adquirió formalidad dentro de los cauces judiciales, por cuanto ya no se trataba sólo de una expresión verbal al ser citados o de firmar en apoyo las solicitudes, sino que en 1856 un pedido ante el juzgado general fue completado con un oficio en el que quienes rubricaban, afirmaban que de "nuestra libre y espontánea voluntad" cedían el derecho, y para que en

${ }^{35}$ Faustina Núñez se le ponga en posesión de su derecho de agua concedido por el juzgado. 7 de febrero de 1853. Irrigación. Carpeta 102, doc. 23. AGPM, Argentina.

${ }^{36}$ Nazario Ferreyra solicita se le dé permiso para sacar una acequia del río Tunuyán. 2 de octubre de 1848. Irrigación. Carpeta 101, doc. 41. AGPM, Argentina; Doña Luciana Gómez de Alanis solicita se le dé derecho a agua para regar sus terrenos en Alto de las Mulas. 24 de abril de 1849. Carpeta 101, doc. 42. AGPM, Argentina; Pedro Charles pide permiso para construir un molino en la acequia de Alto Verde. 23 de septiembre de 1852. Irrigación. Carpeta 102, doc. 14. AGPM, Argentina.

${ }^{37}$ El juez de aguas al ministro de gobierno. 24 de octubre de 1857. Irrigación. Carpeta 104, doc. 77. AGPM, Argentina.

${ }^{38}$ Francisco Sosa solicita merced de agua. 28 de junio de 1855. Irrigación. Carpeta 103, doc. 32. AGPM, Argentina. 
"todo tiempo conste la consesion de dicha servidumbre y se nos compela a su cumplimiento", lo daban. ${ }^{39}$

Hay un último dato: la persistencia del problema generado por las ciénagas y los desbordes de acequias agravado por la mayor extensión de los campos labrados. Aquí también se ve cómo el papel del gobierno provincial, por sí o a través del juzgado general, se fortaleció respecto de problemas que antes eran solucionados por compromisos verbales. En efecto, si bien algunos procesos muestran que los pobladores trataron de solucionar los conflictos generados por derrames antes de arribar a la instancia judicial, ${ }^{40}$ otros revelan que el aumento de la agricultura forrajera vinculada con la ganadería incrementó las filtraciones y los anegamientos debido al predominio de alfalfa que requería mucha agua, gestionada a través del riego por manto (Martín, Rojas y Saldi, 2010, pp. 170-171). Se esbozaba en este contexto la opinión de que sólo la intervención de las autoridades superiores ofrecía una salida duradera. En efecto, en 1850, vecinos de Retamo preocupados por la formación de una laguna se dirigieron al gobierno para pedirle ayuda en la apertura de desagües para desecar la zona. Si bien se presentaban como comunidad comprometida con la obra a realizarse, sostenían que esta los superaba, pues requería un monto de dinero y una sistematicidad de trabajos que sin la vigilancia gubernamental no se podría lograr. La comisión nombrada para informar, integrada por los jueces de aguas provincial y departamental más los ciudadanos designados por el primero y los representantes que cada comunidad de regantes eligió, enumeró las tareas que debían realizarse pero agregó la necesidad de disciplinar prácticas que generaban desagües desordenados: se requería una vigilancia firme para modificar una "costumbre inveterada" ${ }^{41}$ Como se ve, si los esfuerzos reglamentarios no habían domesticado hábitos de riego en un territorio cuya geomorfología agravaba los efectos del riego por manto necesario para los forrajes, cada vez era más claro para quienes se acercaban a la ciudad a pedir ayuda que la mediación gubernamental se presentaba como eficaz solución para ciertos problemas de la gestión hídrica.

${ }^{39}$ Edmundo Day solicita merced de agua. 30 de diciembre de 1856. Irrigación. Carpeta 104, doc. 28. AGPM, Argentina.

${ }^{40}$ Isabel Vargas y Matías Godoy contra los interesados de la acequia de la Villa Nueva de San Martín. 13 de noviembre de 1855. Irrigación. Carpeta 103, doc. 39. AGPM, Argentina.

${ }^{41}$ Bernardo Corvalán y otros solicitan la apertura de unos desagües. 20 de enero de 1850. Irrigación. Carpeta 101, doc. 46. AGPM, Argentina. 


\section{CONSIDERACIONES FINALES}

El trabajo ha indagado en una serie de prácticas de justicia de aguas para observar cómo se tramaron en un territorio los vínculos comunitarios en torno suyo y las relaciones con la conformación de la estatalidad provincial. El análisis ha permitido detectar dos procesos. Por una parte, el esfuerzo voluntarista de sucesivos gobiernos por configurar un espacio político nuevo a partir de la integración de diversos territorios con el fin de ponerlos en productividad dadas las buenas condiciones naturales si se realizaban las obras de irrigación necesarias; ello implicaba también instalar un centro político en una Villa, la Nueva de San Martín, colocando bajo su control una amplia población inicialmente dispersa y con escasos vínculos comunitarios. Por otro lado, bajo este impulso gubernativo, pero también al ritmo de la consolidación de un modelo productivo de ganadería comercial con agricultura subordinada, se fortaleció una comunidad de vecinos propietarios que tenían claro que el uso del agua requería negociaciones y consensos que debían activar ellos mismos más allá de las iniciativas de las autoridades.

Ambos procesos redundaron en la consolidación de una justicia de proximidad que se convirtió en el nervio de la espacialización política de Retamo y Barriales hasta 1859, cuando el primer núcleo fue escindido para formar un nuevo departamento. Esta justicia cercana a la población focalizó su acción en dos aspectos que reprodujeron los lazos comunitarios: la regulación del uso del agua y el control sobre los forasteros, sobre todo los que no tenían oficio útil. La resolución de los conflictos interpersonales a raíz del acceso a la primera conectaba la espacialización con una trama de relaciones en las que se negociaban no sólo la posibilidad de riego sino preeminencias y subordinaciones.

El caso analizado muestra cómo los procesos de estatalidad se articularon de diversos modos con las comunidades que buscaban integrarse en su monopolio territorial, según los caracteres que las relaciones entre sus miembros iban configurando. Sin embargo, también resulta claro que los comportamientos de estos, y las representaciones sobre las que se sostenían, comenzaron a ser progresivamente atravesados por el voluntarismo gubernamental que, a través de diversos dispositivos, pretendía disciplinar y vigilar hábitos según sus propios proyectos productivos. En tal sentido, no conviene perder de vista que el estado mendocino comenzó a organizarse al pulso de un modelo ganadero y que las tierras del departamento de San Martín se orienta- 
ron específicamente hacia el cultivo forrajero. De este modo, al menos en el periodo estudiado, las estrategias de estatalización configuraron un espacio para la participación de los regantes en la gestión de su recurso, reconociendo su derecho a opinar sobre situaciones que afectasen la distribución vigente. Este caso muestra una forma de estatalidad que no oponía el Estado a los usuarios, sino que los articulaba en una relación en la que se reconocía que los mejores administradores del agua eran quienes dependían de ella para su subsistencia, aun cuando se reservaba vías para intervenir regularmente y tendió a sistematizarlas. Una modalidad de vínculo estatal con comunidades de regantes legalmente reconocidas y sostenidas que se asemejaba, en parte, a la sancionada en 1866 en España, a partir de la cual se definió un conjunto de relaciones que combinaba la colaboración estatal-comunitaria, una aceptación selectiva de la autonomía y una acción determinada del primero para modificar normas e instituciones (Calatayud, 2016, p. 34).

Tanto los caracteres geomorfológicos del territorio como la emergencia de una esfera pública desde la revolución que introdujo prácticas eleccionarias, favorecieron modalidades de gestión hídrica que no sólo generaron reglamentaciones específicas para este departamento, sino la institucionalización de comunidades de regantes activas dentro de un panorama provincial en el que existía la elección de jueces de acequias por los usuarios pero parecieron no generar dinámicas tan intensas como aquí. De hecho, la trama hídrica conforma hasta hoy un patrimonio comunitario básico dentro de la identidad local departamental de San Martín y Junín, como lo expresa el nombre del antiguo canal abierto por Herrera en 1815, llamado Acequia de la Patria, todavía en uso al igual que las cuatro acequias dispuestas por el Reglamento de 1837 (Guirini et al, 2014, p. 81). Y hay que marcar que si bien con bastante posterioridad al periodo estudiado, la orientación ganadera de la agricultura fue reemplazada por diversos cultivos, sobre todo por viñedos (Martín et al, 2010, pp. 170-171) que sostienen hoy una notable industria vitivinícola, aquella no hizo más que ampliar y complejizar las tramas hídricas heredadas del siglo XIX (Guirini, Médico y Vichi, 2014, pp. 71 y 73). ${ }^{42}$

${ }^{42}$ Agradezco las referencias otorgadas en estos aspectos por el prof. Alejandro Ravazzani. 


\section{LISTA DE REFERENCIAS}

Abrams, P. (1988). Notes on the difficulty of studying the state. The Journal of Historical Sociology, 1(1), 58-89.

Acevedo, E. O. (1979). Orígenes de la organización judicial de Mendoza. Mendoza: Fundación para la Educación, la Ciencia y la Cultura.

Agüero, A. (2013). Derecho local y localización del derecho en la tradición jurídica hispana. Reflexiones a partir del caso de Córdoba del Tucumán. En V. Tau Anzoátegui y A. Agüero (coords.), El derecho local en la periferia de la monarquía hispana. Río de la Plata, Tucumán y Cuyo. Siglos XVI-XVIII (pp. 91-120). Buenos Aires: INHIDE.

Ahumada, M. (1860). Código de las leyes, decretos y acuerdos que sobre Administración de Justicia se ha dictado la Provincia de Mendoza. Mendoza: El Constitucional.

Barral, M. E., Fradkin, R. y Perri, G. (2007). ¿Quiénes son los "perjudiciales"? Concepciones jurídicas, producción normativa y práctica judicial en la campaña bonaerense (1780-1830). En R. Fradkin (ed.), El poder y la vara. Estudios sobre la justicia en el Buenos Aires rural (pp. 129-153). Buenos Aires: Prometeo.

Barriera, D. (2012a). Instituciones, justicia de proximidad y derecho local en un contexto reformista: designación y regulación de "jueces de campo" (Gobernación-Intendencia de Buenos Aires) a fines del siglo xviII. Revista de Historia del Derecho, 44, 1-28. Recuperado de http://www.scielo.org.ar/scielo. php?script=sci_issuetoc\&pid=1853-178420120002\&lng=es\&nrm=iso

Barriera, D. (2012b). Justicia de proximidad: pasado y presente, entre la historia y el derecho. Pol-His Boletín Bibliográfico Electrónico del Programa Buenos Aires de Historia Política, 10, 50-57. Recuperado de http://archivo.polhis.com.ar/datos/PolHis\%20 10.pdf

Barriera, D (2015). Al territorio por el camino de la memoria: dos jueces rurales evocan y listan a los habitantes de su jurisdicción y sus actividades económicas (Pago de los Arroyos, Santa Fe del Río de la Plata, 1738). Mundo Agrario, 15(30). Recuperado de http://www.mundoagrario.unlp.edu.ar/

Bourdieu, P. (1996). Espíritus de Estado. Génesis y estructura del campo burocrático. Sociedad, 8, 5-29.

Calatayud, S. (2016). Antes de la política hidráulica: la gestión del agua bajo el Estado liberal en España (1833-1866). Historia Agraria, 68, 13-40. Recuperado de http:// www.historiaagraria.com/numero.php?n=68

Calatayud, S. y Garrido, S. (2012). Negociación de normas e intervención estatal en la gestión del regadío. La acequia Real del Júcar a mediados del siglo xIX. Hispania. 
Revista Española de Historia, LXXII(240), 95-118. Recuperado de http://hispania.revistas.csic.es/index.php/hispania/issue/view/34

Cano, G. (1941). Régimen jurídico-económico de las aguas en Mendoza. Durante el periodo intermedio (1810-1884). Mendoza: García Santos.

Corrigan, P. y Sayer, D. (1985). The great arch. English state formation as cultural revolution. Oxford: Basil Blackwell.

Das, V. y Poole, D. (2008). El Estado y sus márgenes. Etnografías comparadas. Cuadernos de Antropología Social, 27, 9-52.

Doucet, G. (1983). La administración de aguas en La Rioja bajo el régimen español: aportes para su estudio. Revista de Historia del Derecho, 11, 491-506.

Dougnac Rodríguez, A. (1984). Régimen jurídico de las aguas en Chile durante el siglo XVI. Revista Chilena de Historia del Derecho, 10, 51-78.

Dougnac Rodríguez, A. (1985). El Cabildo y el derecho de aguas en Santiago de Chile en los siglos XVII y XVIII. Revista Chilena de Historia del Derecho, 11, 277-313.

Dougnac Rodríguez, A. y Barrientos Grandón, J. (1991). El derecho de aguas a través de la jurisprudencia chilena de los siglos XVII y xviII. Revista de Estudios Histórico-Jurídicos, xIV, 101-136.

Draghi Lucero, J. (1941). San Martín, su chacra, su molino y la ubicación de su primer monumento. En Anales del Instituto de Investigaciones Históricas (t. I, pp. 551-622). Mendoza: Universidad Nacional de Cuyo.

Galante, Mirian (2011). México, siglo xix: perspectivas, temas y aportes. Revista Complutense de Historia de América, 37, 93-115. DoI: http://dx.doi/org/10.5209/rev_ RCHA.2011.v37.5

Garavaglia, J. C. (1999). "Pobres y ricos": cuatro historias edificantes sobre el conflicto social en la campaña bonaerense (1820-1840). En J. C. Garavaglia, Poder, conflicto y relaciones sociales. El Río de la Plata, XVIII-XIX (pp. 29-56). Rosario: Homo Sapiens.

Garavaglia, J. C. (2011). ¿Cómo se mide la tierra? Las mensuras en el Río de la Plata, siglos XVII-XIX. En J. C. Garavaglia y P. Gautreau (eds.), Mensurar la tierra, controlar el territorio. América Latina, siglos XVIII-XIX (pp. 27-61). Rosario: Prohistoria/State Building in Latin America.

Garrido, S. (2011). Las instituciones de riego en la España del este. Una reflexión a la luz de la obra de Elinor Ostrom. Historia Agraria, 53, 13-42. Recuperado de http:// www.historiaagraria.com/numero.php?n=53

Garriga, C. (2004). Orden jurídico y poder político en el antiguo régimen. ISTOR. Revista de Historia Internacional, 16, 13-44. Recuperado de http://istor.cide.edu/ archivos/num_16/dossierl.pdf

Guha, R. (2002). Las voces de la historia. Barcelona: Crítica. 
Guirini, L., Médico, C. y Vichi, J. (2014). Paisaje vitivinícola en el Departamento de General San Martín, Mendoza. Debilidades y potencialidades. Proyección, 17, 70-93. Recuperado de http://bdigital.uncu.edu.ar//objetos_digitales/7504/05-proy-girini.pdf

Ingold, A. (2008). Les sociétés d'irrigation: bien commun et action colective. Entreprises et Histoire, 50, 19-35. Recuperado de http://entrepriseshistoire.ehess.fr/ avril-2008-n-50-156-pages-gestion-de-leau-conflits-ou-cooperation/

Irurozqui, M. (2016). Presentación: Otra vuelta de tuerca. Justicia y violencia política en Iberoamérica, siglo xIX. Revista de Indias, LXXVI(266), 3-16. Recuperado de http://revistadeindias.revistas.csic.es/index.php/revistadeindias/issue/view/105

Mannori, L. (2007). Justicia y administración, entre antiguo y nuevo régimen. Revista Jurídica. Universidad Autónoma de Madrid, 15, 125-146.

Margadant, G. (1989). El agua a la luz del derecho novohispano. Triunfo de realismo y flexibilidad. Anuario Mexicano de Historia del Derecho, 1, 113-146.

Mariluz Urquijo, J. M. (1951). Contribución a la historia de nuestro derecho de aguas. Un reglamento catamarqueño de 1797. Trabajos y Comunicaciones, 2, 78-88.

Martín, F., Rojas, F. y Saldi, L. (2010). Domar el agua para gobernar. Concepciones socio-políticas sobre la naturaleza y la sociedad en contextos de consolidación del Estado provincial mendocino hacia finales del siglo xIX y principios del xx. Anuario del Centro de Estudios Históricos "Prof. Carlos S. A. Segreti", 10, 159-186. Recuperado de http://cehsegreti.org.ar/archivos/FILE_00000361_1411759985.pdf

Martínez, P. S. (1961). Historia económica de Mendoza durante el virreinato, 1776-1810. Mendoza: Universidad Nacional de Cuyo.

Martínez, P. S. (1970). Regulación jurídica de la irrigación en Mendoza durante el siglo XVIII (Contribución a la Historia del Derecho de Aguas en Argentina). Revista Chilena de Historia del Derecho, 6, 170-184.

Masini Calderón, J. L. (1979). Algunos aspectos de una política social sanmartiniana en Cuyo. CEIFAR, 3, 133-158.

Mitchell, T. (1991). The limits of the state: beyond statist approaches and their critics. American Political Science Review, 85(1), 77-96.

Molina, E. (2007). Justicia y poder en tiempos revolucionarios: las modificaciones en las instituciones judiciales subalternas de Mendoza (1810-1820). Revista de Historia del Derecho, 35, 269-296.

Molina, E. (2015). Jueces y comandantes en la periferia del Estado provincial Valle de Uco (Mendoza, Argentina), 1820-1852. Revista del Instituto de Historia del Derecho, 49, 1-34. Recuperado de http://www.scielo.org.ar/scielo.php?script=sci_ issuetoc\&pid=1853-178420150001\&lng=es\&nrm=iso 
Molina, E. (2017). Burocratización y prácticas administrativas como estrategias gubernamentales en la campaña mendocina. El caso de la Subdelegacía de la Villa Nueva de San Martín, 1821-1852. Ponencia presentada en las V Jornadas nacionales y I Internacionales de Investigaciones Regionales e Interdisciplinarias, cCt-Conicet, Mendoza, Argentina.

Molina, E. y Yangilevich, M. (2015). Justicia menor y equipamiento institucional de los espacios urbanos y rurales en Hispanoamérica en el tránsito del antiguo régimen al orden republicano, siglos XVII-XIX. Sección Dossier de Programa Interuniversitario de Historia Política. Recuperado de http://historiapolitica.com/dossiers

Morelli, F. (2011). "Entre confianza y armas”. La justicia local en Ecuador del antiguo régimen al liberalismo. Revista Complutense de Historia de América, 37, 27-47. Recuperado de https://revistas.ucm.es/index.php/RCHA/issue/view/2209/showToc

Ostrom, E. (2000). El gobierno de los bienes comunes. La evolución de las instituciones de acción colectiva [1990]. México: CRIM-UNAM/Fondo de Cultura Económica.

Pascualotto, M. E. (2017). Las políticas hídricas y el proceso constitucional de Mendoza. Área Metropolitana (1561-1916). Mendoza: Editorial de la Facultad de Filosofía y Letras-UNCuyo.

Pérez Picazo, M. T. (2000). Nuevas perspectivas en el estudio del agua agrícola. La subordinación de la tecnología a los modos de gestión. Historia Agraria, 22, 37-56. Recuperado de http://www.historiaagraria.com/numero.php?n=22

Prieto, M. del R., Rojas, F., Castrillejo, T. y Hernández, F. (2012). Procesos ambientales y construcción del territorio a partir de un estudio de caso: la ciénaga de Bermejo, oasis Norte de Mendoza, 1810-1930. Revista de Historia Argentina y Americana, 47(2), 175-207. Recuperado de http://bdigital.uncu.edu.ar/7111

Richard Jorba, R. (1998). Poder, economía y espacio en Mendoza (1850-1900). Del comercio ganadero a la agroindustria vitivinícola. Mendoza: Facultad de Filosofía y Letras-UNCuyo.

Salazar, G. (2000). Labradores, peones y proletarios, Santiago: LOM.

Sanjurjo, I. (2004). La organización político-administrativa de la campaña mendocina en el tránsito del antiguo régimen al orden liberal. Buenos Aires: INHIDE.

Sanjurjo, I. (2011). Repartir sin pasión ni afición. Prácticas jurídicas en torno al uso del agua en Mendoza virreinal. En M. P. Polimene (coord.), Autoridades y prácticas judiciales en el antiguo régimen. Problemas jurisdiccionales en el Río de la Plata, Córdoba, Tucumán, Cuyo y Chile (pp. 157-180). Rosario: Prohistoria.

Sanjurjo, I. (2015). Justicias inferiores y gobierno en espacios rioplatenses (siglo XVIII y primera mitad del siglo xIx). Nuevo Mundo. Mundos Nuevos, Débats. Recuperado de http://nuevomundo.revues.org/67871 
Vives, C. (1990). El régimen jurídico de las aguas en Córdoba (1573-1805). Revista de Historia del Derecho, 18, 465-524.

Weber, M. (1969). Economía y sociedad (t. I). México: Fondo de Cultura Económica.

\section{OTRAS FUENTES}

\section{Archivos}

Agpm Archivo General de la Provincia de Mendoza, Argentina. 